\title{
Biosecurity Practices and Characteristics of Poultry Farms in Three Regions of Cameroon
}

\author{
Fabrice De Paul Tatfo Keutchatang ${ }^{1}$, Isabelle Sandrine Bouelet Ntsama ${ }^{2 *}$, Gabriel Medoua Nama ${ }^{3}$, and Germain Kansci ${ }^{1}$ \\ ${ }^{1}$ Department of Biochemistry, Laboratory for Food Science and Metabolism, Faculty of Sciences, University of Yaoundé 1, PO box 812, Yaoundé, Cameroon \\ ${ }^{2}$ Advanced Teacher's Training College for Technical Education, University of Douala, PO box 1872, Douala, Cameroon \\ ${ }^{3}$ Centre for Food and Nutrition Research, IMPM, PO Box 6163, Yaoundé, Cameroon \\ *Corresponding author's Email: ibouelet@yahoo.fr; ORCID: 0000-0003-3638-8142
}

Received: 04 Jan. 2021

Accepted: 19 Feb. 2021

\begin{abstract}
The outbreak of diseases is the main factor affecting poultry production in Cameroon. The implementation of biosecurity measures in poultry farms is essential to reduce disease outbreaks. This study aimed to assess biosecurity practices in poultry farms in three regions of Cameroon. The study was carried out using a structured questionnaire on 90 randomly selected poultry farms. Most of the farmers were men (85\%) with deep litter $(77.8 \%)$, battery cage $(2.2 \%)$, and both deep litter and battery cage (20.0\%) housing systems. Amongst the farms surveyed, $9 / 30(30.0 \%)$ in the Centre; $8 / 30$ (26.7\%) in the Littoral; and 13/30 (43.3\%) in the West were aware of biosecurity measures. The biosecurity score (BS) of surveyed farms ranged between 2 and 3. The findings indicated that 39 farms (12 in the Centre, 14 in the Littoral, and 13 in the West) were at moderate risk, and 51 farms (18 in the Centre, 16 in the Littoral, and 17 in the West) were at high risk. Reasons for keeping chickens and the number of chickens per farm did not significantly influence BS, while the farm category could significantly affect it. The outbreak of diseases correlated with BS, showing a tendency of increase in the outbreak of diseases with increasing BS. This study underlines the fact that biosecurity practices in Cameroon have not been well implemented by chicken farmers. This leads to disease outbreaks, and consequently, important economic losses as well as massive use of drugs that may be unsafe for human consumption. Therefore, the effective monitoring of biosecurity in chicken farming should be encouraged by extension of training to the farmers to support the efficient production of chickens by respecting biosecurity that drastically reduces the risk of disease outbreaks and provides good quality chicken products for human consumption.
\end{abstract}

Keywords: Assessment, Biosecurity practices, Biosecurity scores, Cameroon, Poultry farms

\section{INTRODUCTION}

Chicken farming is a growing sector in Cameroon that creates income generation in rural and urban areas (Guetiya et al., 2016), representing a good source of essential nutrients. Amongst food animals, chicken production is quicker and cheaper than other meat sources. In addition, chicken products gain more attention in Islamic countries due to religious rules forbidding the consumption of some animal meats, such as pork, and therefore, play an important role in public nutrition (Paryad and Mahmoudi, 2008; Melesse, 2014; Sambo et al., 2015). The necessity of securing the food supply in terms of quality and quantity, consumers' awareness, and tendency to maintain a healthy and balanced diet, have all made the poultry sector a significant industry throughout the world (Aral et al., 2013).
Some infectious diseases, such as Highly Pathogenic Avian Influenza (HPAI) are zoonotic, resulting in a range of mild to serious diseases having fatal consequences in both poultry and humans (Beeckman and Vanrompay, 2009; WHO, 2011). The unprecedented widespread outbreaks of HPAI, which has occurred in many countries in Asia, Europe, and Africa since 2003, call for rapid and active response at regional, national, and international levels. Biosecurity is a key strategy to reduce the incidence of outbreak diseases, such as HPAI, by applying technical recommendations at the farm or poultry house (DAFF, 2011; Newell et al., 2011). Biosecurity measures are necessary to prevent the negative consequences of infectious diseases during chicken farming because they reduce the introduction, persistence, or dissemination of infectious agents (Loth et al., 2011), and minimize the direct and indirect negative economic effect of infections 
on stakeholders (farmers, customers, and suppliers) (Can and Altuğ, 2014). Furthermore, biosecurity measures are vital for better performance and quality of chicken production in the competitive world.

Various assessment studies have highlighted substantial weaknesses in the implementation of biosecurity measures in chicken farms (Abdurrahman et al., 2016; Maduka et al., 2016; Yitbarek et al., 2016). In Cameroon, few studies have assessed biosecurity practices. Kouam and Moussala (2018) studied the level of implementation of biosecurity measures on small-scale broiler farms in the Western Highlands of Cameroon and found that level of implementation was poor and there was a significant relationship between farm biosecurity score (BS) and farm production system.

The HPAI H5N1 virus has caused widespread mortality in the poultry sector among many African countries (Egypt, Ethiopia, and Nigeria). This situation of disease outbreaks, particularly in Cameroon has raised a concern about the level of implementation of biosecurity measures on chicken farms (MINEPIA, 2009). The present article outlines the biosecurity practices implementation on chicken production with the aim of contributing to improving chicken management practices in resourcelimited conditions, specifically in Cameroon. The current study had three objectives of appraising the chicken production system, assessing the level of biosecurity practices, and examining any relationship between the biosecurity practices and the socio-technical characteristic of farms and farmers in three regions of Cameroon.

\section{MATERIALS AND METHODS}

\section{Study areas}

The study was conducted in three regions of Cameroon, including the center, the littoral, and the west regions (Figure 1). The central region covers $68926 \mathrm{~km}^{2}$ and is composed of rolling hills on a vast plain with a mean altitude of $700-800 \mathrm{~m}$, with lowered mounds. The climate has two wet seasons. The population density is low, with about 36 inhabitants $/ \mathrm{km}^{2}$ (NIS, 2006; BUCREP, 2010). The littoral region has an area of $20239-\mathrm{km}^{2}$ with more than $2,202,340$ inhabitants. The population density is 124 inhabitants $/ \mathrm{km}^{2}$. The west region represents an area of $13872 \mathrm{~km}^{2}$ characterized by highlands with a mean altitude of $1600 \mathrm{~m}$ and narrow valleys with catchments separating them. The population density is estimated at 143 inhabitants $/ \mathrm{km}^{2}$ (BUCREP, 2010).

\section{Study design and data collection}

Study areas were selected as they could represent a high potential for chicken production due to favorable conditions (Teleu Ngandeu and Ngatchou, 2006). Data were collected using structured questionnaires. The data were collected from governmental authorities and poultry farmers by data collector/field assistants. The research team worked in partnership with local veterinary agencies to recruit participants since most of them are scared of sanitary control by governmental authorities. The farms were randomly selected; 30 farms in the center, 30 farms in the littoral, and 30 farms in the western regions. The objective of the study was explained to the farmers and their verbal informed consent was obtained before administering the questionnaire. Chicken farms were evaluated for biosecurity practices and scored. Biosecurity measures were grouped according to some indicators of biosecurity events (events outside the premises, events at the farm boundary, events between farm boundary and poultry house, events inside poultry house).

\section{Questionnaire design}

A set of preliminary questionnaires were prepared and tested with 10 farmers in Yaoundé, Cameroon for biosecurity practices a few months after the avian influenza outbreak. Thus, necessary modifications were made based on the feedback and the final questionnaire was prepared based on the pilot survey. The structured questionnaire with both open-ended and closed questions was applied to 90 chicken farmers or farm employees by a team of two persons, the interview lasted for 45-60 minutes. The questionnaire had three parts: 1)sociodemographic characteristics of farmers, 2) information about poultry farming systems, 3 ) inquiry into biosecurity measure implementation.

\section{Biosecurity scoring system}

The scoring system used in this study was developed from the biosecurity indicators observed in the evaluation of biosecurity practices on the farm as previously reported with scores of 0-3. Criteria used for scoring biosecurity practices were adopted from USAID (2009). Thirty-three biosecurity indicators were recorded and characterized with scores of 0-3 (3.00 for the worst incorrect practice,2.00 for the occasional respect of biosecurity measures, 1.00 for average compliance with biosecurity measures of biosecurity measures, and 0.00 for the best correct practice). The BS of each farm was the average of 
the scores of the biosecurity indicators. Accordingly, a low mean BS value indicates a higher level of biosecurity.

\section{Statistical analysis}

Data were analyzed by SPSS software, version 20.0. Categorical variables were expressed using frequencies and percentages while continuous variables, such as BS of farms, were expressed as means and standard deviations. The associations and relationships were assessed using the Chi-square test and Pearson's correlation, respectively, and variations in means were assessed by one-way ANOVA followed by Tukey post hoc test. The difference was considered significant for a p-value $<0.05$ with a confidence interval of $95 \%$.

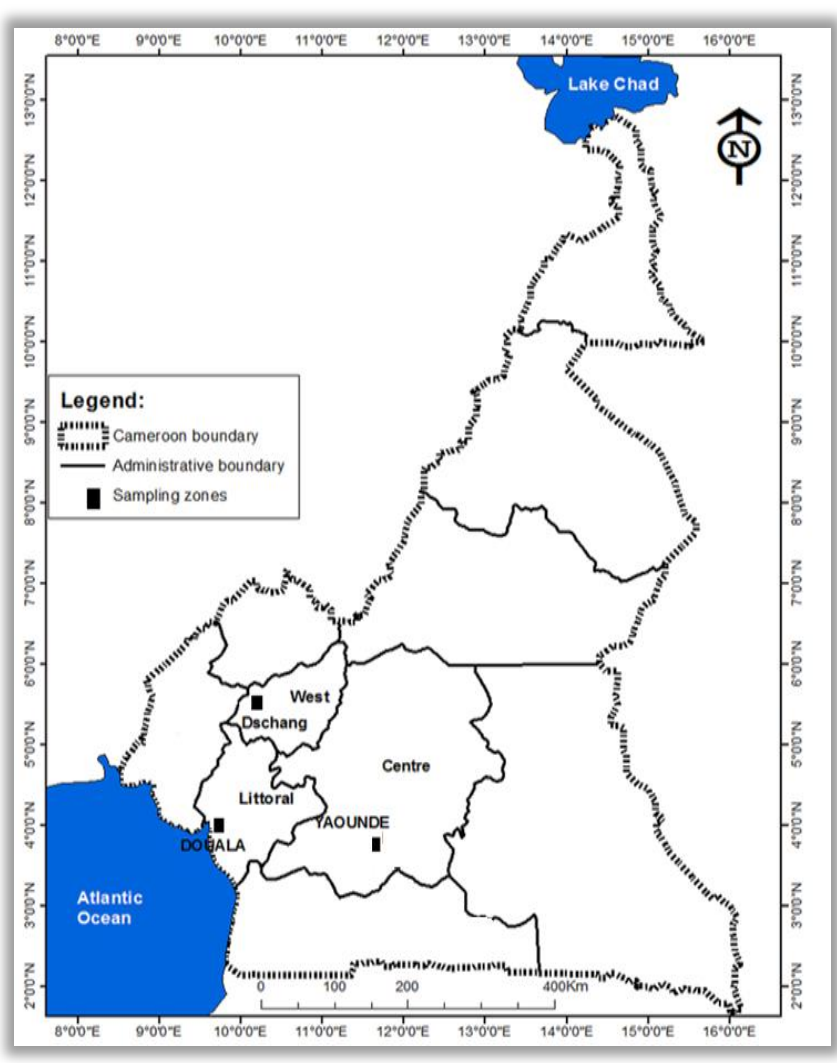

Figure 1. The map of Cameroon showing study areas marked by small black squares.

\section{RESULTS}

\section{General characteristics of the studied farms}

The participating farmers were mostly men (85\%), and most of the farmers $(74.4 \%)$ had no formal training in chicken production and $60 \%$ of farmers had more than three years of experience (Figure 2). Diseases were the most constraint faced by chicken farmers (100.0\%), followed by financial constraints $(93.3 \%)$. Some farmers (13.3\%) produced chickens for only family consumption, while others $(20.0 \%)$ produced for family consumption and also sold the surplus. The higher percentage of farmers (66.7\%) who own the majority of chickens $(97.5 \%)$ produced chickens for only commercial purposes. Farms make income from the sale of live chickens and table eggs to fecal droppings to crop farmers and carcasses of dead chickens to breeders. The flock size in the surveyed farms ranged from 50-10,000 chickens. About ten $(12.2 \%)$ of farms hosted 200-500 chickens, followed by $501-1000$ birds (15.6\% of farms), and 1001-2000 chickens (13.3\% of farms). Regarding the age of the chickens, $33.3 \%$ were < 4 weeks, $38.9 \%$ were between 4 to 8 weeks and $27.8 \%$ were $\geq 8$ weeks. The three main types of chicken were broiler (55\%), layer (43\%), and backyard chickens (2\%). Three housing systems of chicken farming were deep litter system (77.8\%), combination of the deep litter with battery cages (20.0\%), and battery cages $(2.2 \%)$. The deep litter housing system hosted $97.9 \%$ of the total chicken population (TCP). Ninety-three percent of farms affirmed using veterinary drugs for disease control. The veterinary drugs used were obtained from veterinary pharmacies, markets, and uncertified/unknown sources. Reasons for production, flock size, age of birds, housing system, as well as sources of day-old chicks, feed, and veterinary drugs are presented in Table 1.

Table 1. Characterization of different poultry farms surveyed

\begin{tabular}{|c|c|c|}
\hline Variables & Number of farms (\%) & Number of birds (\%) \\
\hline \multicolumn{3}{|l|}{ Reason for keeping birds } \\
\hline Commercial & $60(66.7)$ & $107100(97.5)$ \\
\hline Family consumption & $12(13.3)$ & $140(0.1)$ \\
\hline Both (semicommercial) & $18(20.0)$ & $2590(2.4)$ \\
\hline \multicolumn{3}{|c|}{ Number of birds per farm } \\
\hline$<200$ & $11(12.2)$ & $7930(7.2)$ \\
\hline $200-500$ & $16(17.8)$ & $6900(6.3)$ \\
\hline $501-1000$ & $14(15.6)$ & $29000(26.4)$ \\
\hline $1001-2000$ & $12(13.3)$ & $35800(32.6)$ \\
\hline $2001-10000$ & $37(41.1)$ & $30200(27.5)$ \\
\hline \multicolumn{3}{|l|}{ Age of birds at study time } \\
\hline$<4$ weeks & $30(33.3)$ & $45170(41.1)$ \\
\hline 4-8 weeks & $35(38.9)$ & $33450(30.5)$ \\
\hline$\geq 8$ weeks & $25(27.8)$ & $31210(28.4)$ \\
\hline \multicolumn{3}{|l|}{ Housing system } \\
\hline Deep litter & $70(77.8)$ & $107490(97.9)$ \\
\hline Battery cage & $2(2.2)$ & $2000(1.8)$ \\
\hline Both & $18(20.0)$ & $340(0.3)$ \\
\hline \multicolumn{3}{|c|}{ Source of day-old chicks and feed } \\
\hline AGROCAM & $5(5.6)$ & $7500(6.8)$ \\
\hline ALIVET & $5(5.6)$ & $3000(2.7)$ \\
\hline BELGOCAM & $6(6.7)$ & $10000(9.1)$ \\
\hline NAPCAM & $5(5.6)$ & $3000(2.7)$ \\
\hline SPC & $18(20.0)$ & $36900(33.5)$ \\
\hline ALIVET/SPC & $5(5.6)$ & $1400(1.2)$ \\
\hline SOCAVE & $6(6.7)$ & $4500(4.1)$ \\
\hline NAPCAM/SPC & $5(5.6)$ & $4000(3.6)$ \\
\hline SPC/AGROCAM & $9(10.0)$ & $16000(14.6)$ \\
\hline Unknown & $26(28.6)$ & $23530(21.4)$ \\
\hline \multicolumn{3}{|c|}{ Source of veterinary drugs } \\
\hline Veterinarypharmacy & $52(57.8)$ & $89980(82.1)$ \\
\hline Market & $22(24.4)$ & $7300(6.7)$ \\
\hline Unknown & $16(17.8)$ & $12280(11.2)$ \\
\hline
\end{tabular}




\section{Biosecurity implementation in farms surveyed}

Positive responses on biosecurity indicators for each region are presented in Table 2. Biosecurity indicators with more than $80 \%$ of positive responses in all three regions were concerning appropriate carcass disposal, rodent-proof, disinfecting feeders/drinkers regularly, prophylactic chemotherapy to healthy chickens, usage of veterinary drugs, and presence of diseases in the past three months. Biosecurity indicators with less than $50 \%$ positive responses in all three regions included awareness of biosecurity practices, washing/disinfecting of vehicles, onfarm necropsy, separation of chicken according to types and age, chickens occasionally allowed to move out of the poultry house. The mean BS ranged between 2 and 2.8 (Table 3). The difference was significant among the mean BS of Centre, Littoral, and West regions ( $\mathrm{p}<0.001$ ). Regarding the obtained data, 12 chicken farms in the Centre region, 14 chicken farms in the Littoral region, and
13 chicken farms in the West region were at moderate risk $(\mathrm{BS}=2)$, while 18 chicken farms in the Centre, 16 chicken farms in the Littoral regions, and 17 in the West region were at high risk $(\mathrm{BS}=3)$. The $\mathrm{BS}$ means varied with the reason of keeping chickens as well as with the flock size (Table 3). The BS was significantly influenced by the farmer category $(\mathrm{p}=0.004)$. Table 4 shows that the flock size did not significantly $(p>0.05$ ) affect the BS and disease outbreaks. However, variations of mean BS amongst farms were significant $(\mathrm{F}=4.171, \mathrm{p}=0.046)$ and the highest mean BS was in farms with $\leq 1,000$ chickens. Disease outbreaks did not correlate with BS, showing a tendency to increase disease outbreaks with increasing BS. The reason for keeping chickens did not significantly $(p>0.05)$ affect disease outbreak within the last three months. In general, chicken farms with low flock size were more at risk than high flock size farms and had disease outbreaks as a major constraint.

Table 2. Percentage of poultry farms with positive responses on indicators of biosecurity events

\begin{tabular}{|c|c|c|c|}
\hline Indicators of biosecurity events & \multicolumn{3}{|c|}{ Number (\%) of farms with "yes" response } \\
\hline Awareness of biosecuritypractices & $9(30.0)$ & $8(26.7)$ & $13(43.3)$ \\
\hline Acquisition of second-hand equipment & $7(23.3)$ & $20(66.7)$ & $13(43.3)$ \\
\hline Purchase of veterinary drugs in veterinary pharmacy & $18(60.0)$ & $14(46.7)$ & $13(43.3)$ \\
\hline \multicolumn{4}{|l|}{ Farm boundary events } \\
\hline \multicolumn{4}{|l|}{ Events between farm boundary and poultry house } \\
\hline Presence of good feed storage facility & $27(90.0)$ & $15(50.0)$ & $24(80.0)$ \\
\hline Appropriate carcass disposal & $22(73.3)$ & $4(13.3)$ & $9(50.0)$ \\
\hline On-farm necropsy & $14(46.7)$ & $0(0.0)$ & $11(36.7)$ \\
\hline Certified commercial feed sources only & $19(63.3)$ & $8(26.7)$ & $15(50.0)$ \\
\hline Functional footbath at the entrance of poultry house & $12(40.0)$ & $8(26.7)$ & $17(56.7)$ \\
\hline \multicolumn{4}{|l|}{ Events inside the poultry house } \\
\hline Separation of chicken according to types and age & $27(90.0)$ & $22(73.3)$ & $19(63.3)$ \\
\hline Proper ventilation & $15(50.0)$ & $11(36.7)$ & $19(63.3)$ \\
\hline Availability of clean water & $15(50.0)$ & $14(46.7)$ & $22(73.3)$ \\
\hline Frequent changing of bedding with dry ones & $22(73.3)$ & $14(46.7)$ & $17(56.7)$ \\
\hline Chickens occasionally allowed to move out of the poultry house & $15(50.0)$ & $1(3.3)$ & $5(16.7)$ \\
\hline Washing/disinfecting poultry house prior to restocking & $30(100.0)$ & $30(100.0)$ & $30(100.0)$ \\
\hline Washing feeders/drinkers regularly & $30(100.0)$ & $27(90.0)$ & $27(90.0)$ \\
\hline Disinfecting feeders/drinkersregularly & $30(100.0)$ & $26(86.7)$ & $8(26.7)$ \\
\hline Isolation of apparently sick chickens & $30(100.0)$ & $25(83.3)$ & $25(83.3)$ \\
\hline
\end{tabular}

Total number of farms surveyed $=90$ 
Table 3. Mean biosecurity score of poultry farms classified according to different parameters

\begin{tabular}{lc}
\hline Parameter & $\begin{array}{c}\text { Mean biosecurity score (Number } \\
\text { of farms) }\end{array}$ \\
\hline Reason for keeping chickens & $2.3 \pm 0.2(60)$ \\
Commercial & $2.6 \pm 0.1(12)$ \\
Semi-commercial & $2.8 \pm 0.1(18)$ \\
Family use only & \\
\hline Number of chickens per farm & $2.7 \pm 0.2(11)$ \\
$<200$ & $2.6 \pm 0.1(16)$ \\
$201-500$ & $2.5 \pm 0.1(14)$ \\
$501-1000$ & $2.4 \pm 0.1(12)$ \\
$1001-2000$ & $2.0 \pm 0.2(37)$ \\
$>2000$ & \\
\hline Farmer category & $2.2 \pm 0.2(23)$ \\
Trained & $2.6 \pm 0.1(67)$ \\
Untrained &
\end{tabular}

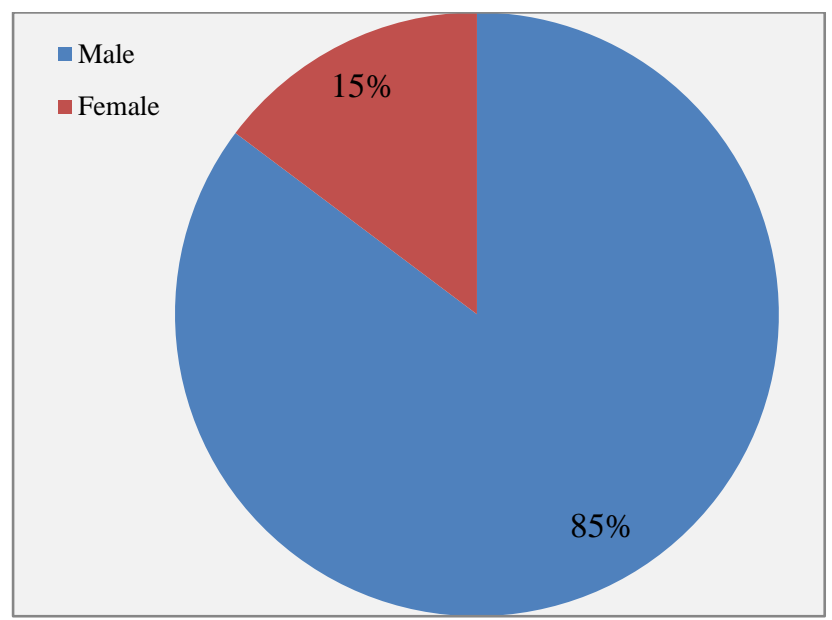

(a) Gender
Table 4. Mean biosecurity scores in poultry farms in three regions of Cameroon

\begin{tabular}{lcccc}
\hline $\begin{array}{l}\text { Study } \\
\text { areas }\end{array}$ & $\begin{array}{c}\text { Mean } \\
\text { biosecurity } \\
\text { scores }\end{array}$ & $\begin{array}{c}\text { Number of } \\
\text { farms (\%) }\end{array}$ & $\begin{array}{c}\text { Number of } \\
\text { farms with } \\
\text { the disease } \\
\text { outbreak }\end{array}$ & $\begin{array}{c}\text { Flock } \\
\text { size }\end{array}$ \\
\hline Center & 2 & $12(40.0)$ & $5(16.7)$ & $>1000$ \\
\hline Littoral & 3 & $18(60.0)$ & $6(20.0)$ & $\leq 1000$ \\
\hline West & 3 & $14(46.7)$ & $4(13.3)$ & $>1000$ \\
\hline Total number of farms surveyed $=90$ & $16(53.3)$ & $6(20.0)$ & $\leq 1000$ \\
\hline
\end{tabular}

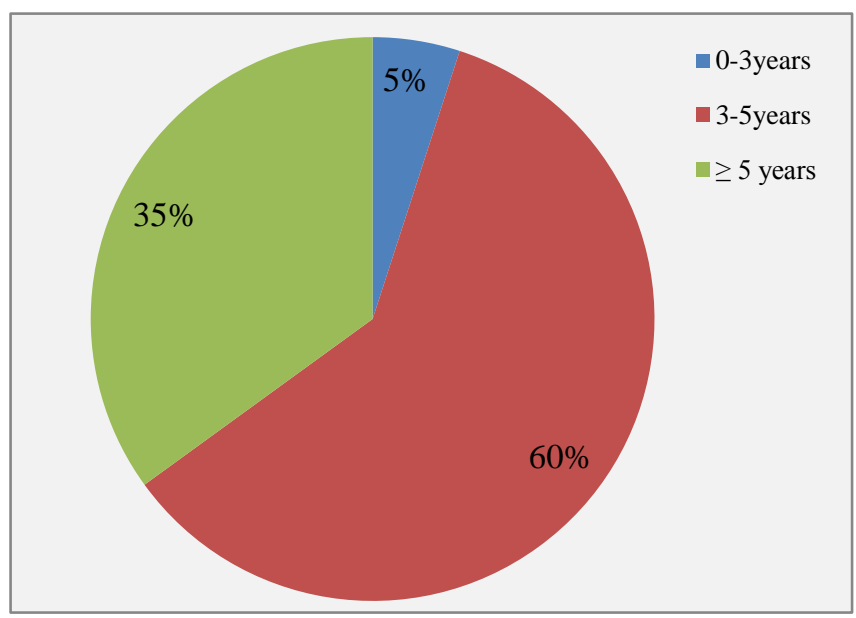

(b) Work experience

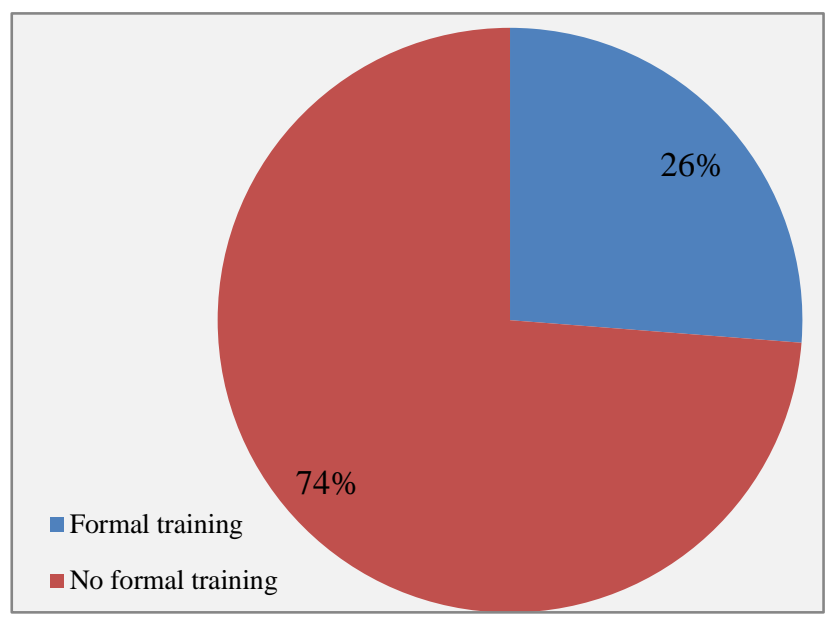

(c) Qualifications in poultryfarming

Figure 2. Characteristics of participating poultry farmers $(n=90)$ in the present study 


\section{DISCUSSION}

The present study assessed the level of implementation of biosecurity practices in chicken farming and their possible impacts on poultry quality in three regions of Cameroon. Poultry farmers were mostly males and most of them were not trained in poultry production or biosecurity measures. Similar to the present study, previous studies have also shown that poultry farming is male dominant. Women are usually more involved in activities, such as trade, and growing crops (Abdurrahman et al., 2016; Fongang Fouepe et al., 2017). The level of farmer training significantly influenced biosecurity scores. Farms surveyed were using three main systems of production, but the main production system was the commercial system. This production system is mainly used because of its high productivity and incomes. Semi-commercial and family production systems also contribute to the provision of chicken and eggs as well as income generation but at a low level.

Unfortunately, during the present study, disease outbreaks were still the main constraint faced by all the farmers $(100.0 \%)$ as earlier reported by Fongang Fouepe et al. (2017). This constraint could be responsible for the uncontrolled usage of veterinary antibiotics as previously mentioned by Gondam et al. (2016) and Guetiya et al. (2016). In the present study, the flock size of most farms ranged from 200 to 2000 chickens and the chicken population was more concentrated in this range. Abdurrahman et al. (2016) reported a different situation in poultry farms of Zamfara State, Nigeria, where the total chicken population was represented by flock sizes of < 200 chickens and 2001-10000 chickens. The same common flock size was reported by Maduka et al. (2016) in Jos state, Nigeria. Flock size less than 200 chickens was found in family farms, while flock size of 200-500 was found in farms with both semi-commercial and strictly commercial production systems. In fact, family farms in this study were used for only family consumption purposes, and normally, the flock size should be small. Previous studies in Nigeria reported that flock size with less than 200 poultry was found in family farms (Geidam et al., 2011). However, flock sizes higher than 500 chickens were found in both family and commercial farms (Esiobu et al., 2014). A report in Cameroon on the traditional poultry sector revealed the flock size within the range of 4,000-10,000 broilers and 2,000 to 5,000 layers per farm (Ekue et al., 2000; Fongang Fouepe et al., 2017). Broilers were more representative in TCP, followed by layers, while backyard chickens were less. The high representativity of broilers could be explained by the short time of production (six weeks) compared to the production times of the backyard (at least 4 months) and layer (at least 18 months). Muhammad et al. (2010) and Maduka et al. (2016) reported the presence of a higher number of broiler farms than layer farms but more layers represented the TCP in stocking capacity. Chickens were mainly housed on a deep litter during the survey and this could be explained by the fact that the litter is cheaper and available. This observation was reported in previous studies conducted in Nigeria (Muhammad et al., 2010; Geidam et al., 2011; Maduka et al., 2016).

Biosecurity is an important tool for the limitation of disease outbreaks and economic losses as earlier mentioned by Conan et al. (2012) but in the present study, the level of awareness on biosecurity amongst the surveyed chicken farmers was too low. This lack of awareness about biosecurity could be explained by the fact that the majority of chicken farmers were not trained in poultry farming. Poultry farms with trained farmers had a lower mean BS than farms with untrained farmers. During training on poultry production, farmers become aware of biosecurity measures and their importance to prevent the occurrence of some common diseases.

In fact, biosecurity involves a set of measures known as biosecurity measures that can be used for farm classification according to the biosecurity score system. In the present study, biosecurity was attributed to each biosecurity measure, leading to the classification of chicken farms surveyed in two groups according to the USAID (2009) biosecurity score system. These two groups include moderate and high-risk levels. This classification could be justified by the weak awareness of farmers on biosecurity as observed during the survey. Maduka et al. (2016) reported different results in Jos, Nigeria, where chicken farms were classified as good, very good, and excellent according to BS. Nigerian farmers had a good knowledge of the basic biosecurity measures needed for day to day running of poultry farms especially the ones dealing with sanitation of the farm (Ajewole and Akinwumi, 2014). Diseases were the major constraints in investigated farms as a result of a failure in biosecurity implementation. Small-scale chicken farms were at a high-risk level, probably because their flock sizes were small, they did not care about it and the economic loss could not be important. In addition, NegroCalduch et al. (2013) reported that biosecurity measures are rarely applied in small-scale production units. In the 
present study, the flock size and the training level of the farmer were major reasons for not complying with certain biosecurity measures. This observation can be justified by the simple fact that failure in biosecurity was remarkable in chicken farms of small flock sizes where farmers were not trained. Furthermore, chicken farms hosting small flock sizes were mostly classified at high risk.

It was also noted that farms located in the Centre were mainly in proximity to humans compared to those in the other two regions, but the movement of people and other animals as well as allowing vehicles inside the gate were observed in the three regions. Several studies identified the proximity of poultry sheds to humans, roads or water bodies, and the movement of objects people and other animals in and out of the sheds, allowing vehicles inside the gate as risk factors for H5N1 outbreaks (Ahmed et al., 2012; Gilbert and Pfeiffer, 2012; Osmani et al., 2014). Failure in biosecurity implementation was remarkable in isolation of apparently sick chickens and functional footbath at the entrance of poultry house in the west region. In the present study, the low percentages of positive responses on biosecurity measures, such as vehicles drove into farm premises without washing and disinfection, farmworkers living outside the farm premises in the majority of farms, separation of chickens according to the type and age, and the use of second-hand equipment, were important components of risk factors. The occurrence of disease outbreaks within the last three months of the present study was one of the consequences of this failure to comply with biosecurity measures. This consequence could be great as several chicken farmers in the three regions investigated affirmed to consult veterinarian only in case of a problem. Other risk factors associated with disease outbreaks were receiving visitors to the farms, rodent-proof, on-farm carnivores, absence of good storage facilities, and non-realization of on-farm necropsy. Receiving visitors to the farms and farm workers living outside the farm premises were risks reported in Nigeria by Fasina et al. (2011), Wakawa et al. (2012), and M'etras et al. (2013). These risks could have serious implications on the spread of contagious poultry diseases by people as well as being of public health importance regarding zoonoses such as avian influenza as reported by Abdurrahman et al. (2016). In this present study, it was observed that failure in biosecurity implementation was associated with the number of chickens in the farm, thus more important was the flock size, more attention was paid to the biosecurity although farms of all flock sizes were at risk. The mean BS was higher in the West region than that in the other regions.
Similarly, Kouam and Moussala (2018) revealed a higher BS for poultry farmers from the West region. A previous study reported that farmers have greater experience in the West (Ngandeu and Ngatchou, 2006). In addition, the capital city of the West region, Bafoussam, is the headquarter of the Cameroonian Association of poultry production professionals known under the acronym of IPAVIC. Thus, West region farmers are supposed to be more endowed with the latest information and innovations in poultry production compared to farmers in the other regions.

Poultry farming is a growing sector in Cameroon and contributes to income-generating (Esiobu et al., 2014; Maduka et al., 2016; Fongang Fouepe et al., 2017), and its products constitute good sources of proteins of high quality and other nutrients for human nutrition (Altan et al., 1993; Seuss-Baum and Nau, 2011). Failure in biosecurity measures could lead to disease outbreaks, causing mortality and important economic losses (Conan et al., 2012). Moreover, disease outbreaks result in the improper use of veterinary drugs, leading to the occurrence of their residues in chicken products (Guetiya et al., 2016; Gondam et al., 2016). It could also lead to drug resistance and transmission of diseases from one farm to another, one animal species to another, and from animal to human.

\section{CONCLUSION}

Three chicken farming systems, including family, semicommercial, and commercial, are applied by chicken farmers in Cameroon. Chicken production generates both incomes and nutrients of high quality but biosecurity measures are not well-practiced and implemented, and this can lead to disease outbreaks and widespread use of veterinary drugs for disease control, resulting in drug resistance and residuals of veterinary drugs in chicken products. It is, therefore, urgent to put in place a good management system that will contribute to increase farm productivity and provide safer chicken products to consumers to fulfill the potential of chicken farming as an engine for the development of Cameroon.

\section{DECLARATIONS}

\section{Authors' contributions}

Fabrice De Paul Tatfo Keutchatang designed the research protocol, collect data, and drafted the manuscript under the guidance of Gabriel Medoua Nama and Germain Kansci. Data were analyzed by Fabrice De Paul Tatfo 
Keutchatang and. Isabelle Sandrine Bouelet Ntsama All activities were coordinated by Gabriel Medoua Nama and Germain Kansci. Finally, all authors read and approved the final edition of the manuscript.

\section{Competing interests}

The authors declare that there is no conflict of interest

\section{Acknowledgments}

We acknowledge the cooperation of the chicken farmers who took part in this investigation because they believe that research and collaborations with scientists are an essential step to ensure the quality and safety of products consumed.

\section{REFERENCES}

Abdurrahman HJ, Muhammad BB, Sanusi MB, Yusuf S, and Fatima MB (2016). Biosecurity measures and constraints among rural poultry farmers in Zamfara State, Nigeria. Animal and Veterinary Sciences, $4(4)$ : 47-51. http://www.doi.org/10.11648/j.avs.20160404.11

Ahmed SS, Ersbøll AK, Biswas PK, Christensen JP, Hannan AS, and Toft N (2012). Ecological determinants of highly pathogenic avian influenza (H5N1) outbreaks in Bangladesh. PLoS One, 7(3): e33938. DOI: http://www.doi.org/10.1371/journal.pone.0033938

Ajewole OC, and Akinwumi AA (2014). Awareness and practice of biosecurity measures in small scale poultry production in Ekiti State Nigeria. IOSR Journal of Agriculture and Veterinary Science, 7: 24-29. DOI: https://doi.org/10.9790\%2F2380071112429

Altan O, Yalçın S, and Kocak C (1993). Egg consumption habits and factors affecting consumption in different segments of society. International Poultry Congress, Istanbul, 178-194. DOI: 10.3906/vet-1102-778

Aral Y, Aydin E, Demir P, Akin AC, Cevger Y, Kuyululu CYK, and Arikan MS (2013). Consumer preferences and consumption situation of chicken meat in Ankara Province, Turkey.Turkish Journal of Veterinary and Animal Sciences, 37(5): 582-587. DOI: http://www.doi.org/10.3906/sag-1207-99

Beeckman DS, and Vanrompay DC (2009). Zoonotic Chlamydophilapsittaci infections from a clinical perspective. Clinical Microbiology and Infection, 15(1): 11-17. DOI: http://doi.org/www.10.1111/j.1469-0691.2008.02669.x

Central Bureau of the Census and Population Studies (BUCREP) (2010). Censuses of the Cameroonian population. Presses du BUCREP. Available at: http://ghdx.healthdata.org/organizations/centralbureau-census-and-population-studies-cameroon

Conan A, Goutard FL, Sorn S, and Vong S (2012). Biosecurity measures for backyard poultry in developing countries: a systematic review. BMC Veterinary Research, 8: Article number 240. DOI: https://www.doi.org/10.1186/1746-6148-8-240

Can M, and Altuğ N (2014). Socioeconomic implication of biosecurity practices in small-scale dairy farms.The Veterinary Quarterly, 34: 1-7. DOI: https://www.doi.org/10.1080/01652176.2014.951130

Department of Agriculture Forestry, and Fisheries (DAFF) (2011). Confidential discussion Paper (10th draft 2011 Republic of South Africa). Available at: https://www.nda.agric.za
Ekue FN, Poné KD, Mafeni MJ, Nfi AN, and Njoya J (2002). Survey of the Traditional Poultry Production System in the Bamenda Area, Cameroon. Joint FAO/IAEA Division of Nuclear Techniques in Food and Agriculture, Animal Production and Health Section, Vienna (Austria), 205: 15-25. Available at: https://www.inis.iaea.org/search/search.aspx?orig_q=RN:3706248 $\underline{0}$

Esiobu NS, Onubuogu GC, and Okoli VBN (2014). Determinants of income from poultry egg production in Imo State, Nigeria: an econometric model approach. Global Advanced Research Journal of Agricultural Science, 3(7): 187-199. Available at: http://www.garj.org/full-articles/determinants-of-income-frompoultry-egg-production-in-imo-state-nigeria-an-econometric$\underline{\text { model-approach.pdf?view=download }}$

Fasina FO, Rivas AL, Bisschop SP, Stegeman AJ, and Hernandez JA (2011). Identification of risk factors associated with highly pathogenic avian influenza $\mathrm{H} 5 \mathrm{~N} 1$ virus infection in poultry farms, in Nigeria during the epidemic of 2006-2007. Preventive Veterinary Medicine, 98: 204-208. DOI: https://www.doi.org/10.1016/j.prevetmed.2010.11.007

Fongang Fouepe GH, Kana JR, Djiobou Kengmo GM, and Mfewou A (2017). Socioeconomic and technical characteristics of broiler and laying hens layers in peri-urban and urban areas in the city of Dschang, West Cameroon. International Journal of Agricultural Economics, $2(4)$ : 110-121. DOI: https://www.doi.org/10.11648/j.ijae.20170204.13

Geidam YA, Gambo HI, Adamu SB, Grema HA, Dapchi AM, and Sanda KA (2011). An assessment of the biosecurity measures in poultry farms in Borno and Yobe States. Sahel Journal of Veterinary Science, $\quad 10(2)$ : $\quad 83-86 . \quad$ DOI: https://www.doi.org/10.1155/2016/1914692

Gilbert M, and Pfeiffer DU (2012). Risk factor modeling of the spatio temporal patterns of highly pathogenic avian influenza (HPAIV) H5N1: a review. Spatial and Spatio temporal Epidemiology, 3(3): 173-183. DOI: https://www.doi.org/10.1016/j.sste.2012.01.002

Guetiya RE, Zambou NF, Anyangwe FF, Njimou JR, Coman MM, Verdenelli MC, Cecchini C, Silvi S, Orpianesi C, Cresci A et al. (2016). Abusive use of antibiotics in poultry farming in Cameroon and the public health implications. British Poultry Science, 57(4): 483493. DOI: https://www.doi.org/10.1080/00071668.2016.1180668

Gondam M, Tatfo Keutchatang F, Yangoua Mafo H, Kansci G, and Medoua Nama G (2016). Antimicrobial usage in the chicken farming in Yaoundé, Cameroon: a cross-sectional study. International Journal of Food Contamination, 3: Article number 10. DOI: https://www.doi.org/10.1186/s40550-016-0034$\underline{6}$

Kouam MK, and Moussala JO (2018). Assessment of factors influencing the implementation of Biosecurity Measures on pig farms in the Western Highlands of Cameroon (Central Africa). Veterinary medicine international, Article ID 9173646. DOI: https://www.doi.org/10.1155/2018/9173646

Loth L, Gilbert M, Wu J, Czarnecki C, Hidayat M, and Xiao X (2011). Identifying risk factors of highly pathogenic avian influenza (H5N1 subtype) in Indonesia. Preventive Veterinary Medicine, 102(1): 50-58. DOI: https://www.doi.org/10.1016/j.prevetmed.2011.06.006

M'etras R, Stevens KB, and Abdu P (2013). Identification of potential risk factors associated with highly pathogenic avian influenza subtype H5N1 outbreak occurrence in Lagos and Kano States, Nigeria, during the 2006-2007 epidemics. Transboundary and Emerging Diseases, 60(1): 87-96. DOI: https://www.doi.org/10.1111/j.1865-1682.2012.01322.x

Maduka CV, Igbokwe IO, and Atsanda NN (2016). Appraisal of chicken production with associated biosecurity practices in commercial poultry farms located in Jos. Nigeria. Scientifica, Article ID 1914692. DOI: http://www.dx.doi.org/10.1155/2016/1914692 
Melesse A (2014). Significance of scavenging chicken production in the rural community of Africa for enhanced food security. World's Poultry Science Journal, 70: 593-606. DOI: https://www.doi.org/10.1017/S0043933914000646

Ministry of Livestock, Fisheries and Animal Industries (MINEPIA) (2009). Master Plan for the Development of Livestock Industries in Cameroon. Cartography of the Paths, 2: 82. Available at: https://www.reliefweb.int/sites/reliefweb.int/files/resources/health _profile_cameroon_2016_eng.pdf

Muhammad ML, Muhammad U, Ambali AG, and Mani AU (2010). A survey of early chick mortality on small-scale poultry farms in Jos, central Nigeria.International Journal of Poultry Science, 9: 446-449. DOI: https://www.doi.org/10.3923/ijps.2010.446.449

Newell DG, Elvers KT, Dopfer D, Hansson I, Jones P, James S, and Pearson D (2011). Biosecurity-based interventions and strategies to reduce Campylobacter spp. on poultry farms. Applied and Environmental Microbiology, 77(24): 8605-8614. DOI: https://www.doi.org/10.1128/AEM.01090-10

Negro-Calduch E, Elfadaly S, Tibbo Ankers MP, and Bailey E (2013). Assessment of biosecurity practices of small-scale broiler producers in central Egypt. Preventive Veterinary Medicine, 110(2): 253-262. https://www.doi.org/10.1016/j.prevetmed.2012.11.014

National Institute of Statistics (NIS) (2006). Cameroon. Available at: https://www.statistics-cameroon.org

Osmani M, Thornton R, Dhand N, Hoque M, Milon S, and Kalam M (2014). Risk factors for highly pathogenic avian influenza in commercial layer chicken farms in Bangladesh during 2011. Transboundary and Emerging Diseases, 61(6): 44-51. DOI: https://doi.org/10.1111/tbed.12071

Paryad A, and Mahmoudi M (2008). Effect of different levels of supplemental yeast (Saccharomyces cerevisiae) on performance, blood constituents and carcass characteristics of broiler chicks. African Journal of Agricultural Research, 3: 835-842. Available at: $\quad$ https://academicjournals.org/journal/AJAR/article$\underline{\text { stat/AD3847E38476 }}$

Seuss-Baum I, and Nau F (2011). The nutritional quality of eggs. In Improving the safety and quality of eggs and egg products.
Woodhead Publishing, pp. 201-236. Available at: https://www.hal.archives-ouvertes.fr/hal-01454200

Sambo E, Bettridge J, Dessie T, Amare A, Habte T, Wigley P, and Christley RM (2015). Participatory evaluation of chicken health and production constraints in Ethiopia.Preventive Veterinary Medicine, 118(1): 117-127. DOI: http://www.doi.org/10.1016/j.prevetmed.2014.10.014

Teleu Ngandeu E, and Ngatchou A (2006). First Assessment of the Poultry Sector in Cameroon: Structure and importance of the commercial and family poultry sector for a better understanding of the issue of Avian Influenza. Emergency assistance for the control and prevention of Avian Influenza. National Consultants Report. Food and Agricultural Organization, Project OSRO/GLO/MUL, FAO representation Yaoundé, Cameroon, pp. 1-46. Available at: http://www.fao.org/docs/eims/upload/213743/agal_poultrysector cameroun may06 fr.pdf

United States Agency for International Development (USAID) (2009). Biosecurity for farms and markets. Manual for Stop AI in Nigeria, pp. 2-24. Available at: http://www.usaid.gov

Wakawa AM, Oladele SB, Abdu PA, Saidu L, and Mohammed SB (2012). Risk factors for the occurrence and spread of highly pathogenic avian influenza $\mathrm{H} 5 \mathrm{~N} 1$ in commercial poultry farms in Kano, Nigeria. Sokoto Journal of Veterinary Sciences, 10(2): 4051. Available at: https://docplayer.net/30525474-A-study-onawareness-attitudes-and-practices-related-to-avian-influenzaamong-poultry-workers-in-dawakin-tofa-local-government-kanostate-nigeria.html

World health organization (WHO) (2011). Influenza at the HumanAnimal Interface.Summary and assessment as of 5 December 2011 Available at: http://www.who.int/influenza/human_animal_interface/avian_infl uenza/Influenza_Summary_IRA_HA interface.pdf

Yitbarek MB, Mersso BT, and Wosen AM (2016). Disease management and biosecurity measures in small-scale commercial poultry farms in and around Debre Markos, Amhara Region Ethiopia. International Journal of Current Trends in Pharmacobiology and Medical Sciences, 1(2): 27-36. DOI: https://doi.org/10.5897/JVMAH2016.0515 